\title{
Sensitivity of optimized transient storage model parameters to spatial and temporal resolution
}

\author{
Steve Wallis ${ }^{1} \cdot$ Russell Manson $^{2}$ \\ Received: 28 August 2018 / Accepted: 25 January 2019 / Published online: 5 February 2019 \\ (c) The Author(s) 2019
}

\begin{abstract}
The transient storage model is a popular tool for modelling solute transport along rivers. Its use requires values for the velocity and shear flow dispersion coefficient in the main channel of the river together with two exchange rates between the main channel and transient storage zones, which surround the main channel. Currently, there is insufficient knowledge to enable these parameters to be predicted from the type of hydraulic variables that may typically be available. Hence, recourse is made to tracer experiments, which provide temporal solute concentration profiles that can be used to estimate the parameters by optimizing model output to observations. The paper explores the sensitivity of such parameters to the spatial and temporal resolutions used in the optimization of the model. Data from 25 tracer experiments covering a river flow rate range of 300-2250 L/s in a single reach of the river Brock in north-west England were used. The shear flow dispersion coefficient was found to be the most sensitive parameter; the velocity was found to be the least sensitive parameter. When averaged over all the experiments, mean percentage differences in parameter values between a coarse resolution case and a fine resolution case were of the order of $2 \%$ for the velocity, $70 \%$ for the shear flow dispersion coefficient and 30\% and $20 \%$ for the two exchange rates. Since the shear flow dispersion coefficient was found to be small, both in numerical terms and in comparison with an estimate of the total dispersion in the reach, it is suggested that it may be viable to omit the shear flow dispersion term from the model.
\end{abstract}

Keywords Solute transport $\cdot$ Rivers $\cdot$ Transient storage model $\cdot$ Model resolution $\cdot$ Parameter optimization

\section{Introduction}

Probably the most reliable method of quantifying transport and mixing mechanisms in rivers is to undertake an in situ tracer experiment. Most often this entails the instantaneous release of a tracer followed by the measurement of temporal solute concentration profiles at one or more locations downstream of the release point. Assuming that the profiles are of good quality, i.e. the entire profile is captured at a sufficiently high temporal resolution, several methods are available for analysing the data in order to estimate parameters such as the cross-sectional average longitudinal velocity and

Steve Wallis

s.g.wallis@hw.ac.uk

1 School of Energy, Geoscience, Infrastructure and Society, Heriot-Watt University, Riccarton, Edinburgh EH14 4AS, UK

2 School of Natural Sciences and Mathematics, Stockton University, Galloway, NJ 08205-9441, USA the longitudinal dispersion coefficient. These methods range from the very simple (e.g. analysing just the evolution of the peak of the profile) to the more complex (e.g. optimizing the output of a mathematical model of the physical transport processes to all or part of the completely observed profile). Generally, there is a trade-off between a quick, easy analysis of the data and a slower, more sophisticated analysis. It is generally believed that the extra time and effort devoted to the latter is worthwhile because a more encompassing use of the data is more likely to yield reliable information than a simple one. Hence, the majority of studies undertaken since the turn of the century (e.g. Gooseff et al. 2003b; Marion et al. 2008; Briggs et al. 2009; Liao and Cirpka 2011) have focused on estimating transport and mixing parameters by optimizing one or more variants of the transient storage model (TSM). However, except for a few studies concerning parameter identifiability and uncertainty (e.g. Wagner and Harvey 1997; Wagener et al. 2002; Worman and Wachniew 2007; Kelleher et al. 2013; Zaramella et al. 2016), the 
reliability of the information so obtained is rarely assessed, yet alone considered.

In this paper, we consider one issue that has the potential to introduce significant errors into the results obtained when optimizing the TSM. The model consists of a pair of differential equations describing the transport of a conservative solute and contains four parameters that quantify the physical processes of: advection and shear flow dispersion in the main channel of the river; and two-way exchange of solute between the main channel and storage zones, which are located at the banks of, and in the bed of, the main channel. Application of the model entails two components: the numerical solution of the differential equations and the optimization of the model output to tracer data, thus obtaining estimates of the four parameters. This pair of operations is repeated many times until the parameter optimization converges.

There are several sources of error in this procedure among which three are particularly notable: those stemming from the numerical solution of the model equations; those stemming from convergence issues in the optimization; and those stemming from imperfections in the tracer data. This paper considers the first of these and focuses on the impact of spatial and temporal resolution issues in the numerical solution of the model equations. The paper extends some earlier work on this issue (Wallis et al. 2013; Wallis and Manson 2018). The aims of the work are to demonstrate that optimized parameter values are dependent on model resolution and to quantify the potential magnitude of resultant errors in the parameter estimates.

\section{Methodology}

\section{Modelling}

The TSM consists of the following two equations which describe the transport of a conservative solute along a river that consists of a main channel that is surrounded by storage zones:

$\frac{\partial c(x, t)}{\partial t}+U_{\mathrm{TS}} \frac{\partial c(x, t)}{\partial x}=D_{\mathrm{TS}} \frac{\partial^{2} c(x, t)}{\partial x^{2}}+k_{1}(s(x, t)-c(x, t))$

$\frac{\partial s(x, t)}{\partial t}=-k_{2}(s(x, t)-c(x, t))$

Here, $c$ is the cross-sectional average solute concentration, $\mathrm{s}$ is the solute concentration in the storage zones, $U_{\mathrm{TS}}$ is the cross-sectional average flow velocity in the main channel, $D_{\mathrm{TS}}$ is the shear flow dispersion coefficient in the main channel, $k_{1}$ and $k_{2}$ are exchange rates between the main channel and the storage zones $\left(k_{2}=\left(A / A_{\mathrm{s}}\right) k_{1}\right.$ where $A$ and $A_{\mathrm{s}}$ are the cross-sectional areas of the main channel and storage zones, respectively), $x$ is the longitudinal co-ordinate direction, and $t$ is time. Equation (1) represents solute transport in the main river channel, including advection, shear flow dispersion and the effect of transient storage, whilst Eq. (2) represents a dynamic mass balance of solute in the storage zones. In these equations, a first-order exchange mechanism is used to describe the transport of solute between the main channel and the storage zones (and back again). The origins of the model can be traced back to the 1960s (e.g. Thackston and Krenkel 1967), but the model didn't became popular until the 1980s and 1990s (e.g. Bencala and Walters 1983; Runkel and Chapra 1993; Wagner and Harvey 1997; Runkel 1998). More recently, it has become the standard approach, either in its original form or in later modified forms, for many studies of solute transport in rivers (e.g. Wagener et al. 2002; Gooseff et al. 2003a, b; Worman and Wachniew 2007; Marion et al. 2008; Briggs et al. 2009; Liao and Cirpka 2011; Kelleher et al. 2013; Zaramella et al. 2016).

When applied to a river reach, the model simulates the temporal solute concentration profile at the downstream boundary of the reach using specified values of the four (spatially and temporally constant) parameters $U_{\mathrm{TS}}, D_{\mathrm{TS}}, k_{1}$ and $k_{2}$ and using an upstream boundary condition provided by an observed upstream temporal solute concentration profile. A zero dispersive flux downstream boundary condition is usually used together with an initial condition of zero solute concentration throughout the reach. In this study, the numerical solution of the differential equations was achieved using a semi-Lagrangian, finite volume scheme. In Eq. 1, advection was simulated using the method of characteristics, which locates the appropriate spatial location from which information is used to calculate an unknown solute concentration, together with spatial interpolation of a cumulative solute mass function. Dispersion was computed using backward implicit finite differences in time and central differences in space, whilst transient storage was computed using a backward implicit temporal update. Equation 2 was also computed using a backward implicit temporal update. Further details are provided in Manson et al. (2001) and in earlier work cited therein.

\section{Tracer data}

The data used in this study were collected in the mid-1980s as part of a NERC-funded project undertaken by Lancaster University, UK. Data from 25 experiments undertaken in a short reach of the river Brock in north-west England were used. Each experiment consisted of the release of a known mass of Rhodamine WT followed by the measurement of temporal tracer concentration profiles at two longitudinal sites using microcomputer controlled data acquisition systems. The tracer was released using a pump-fed, laterally 
distributed injection system that delivered tracer evenly over the width of the river. This was located about 40 channel widths upstream of the experimental reach. Consideration of likely transverse mixing rates and the analysis in Rutherford (1994) suggests that the tracer would have been well mixed in the experimental reach for most of the river flow rates encountered. The worst cases are the low river flow rates for which an initial mixing distance of about 60 channel widths would have been required for a centre-line injection. For these experiments, this would have been reduced by the laterally distributed injection. Wallis et al. (1987) give further details of the data collection system, and Wallis and Manson (2018) give details on the recent extraction of the data from the original logged files that were archived in the 1980s.

The study reach (length $128 \mathrm{~m}$; mean width $8.5 \mathrm{~m}$; slope 0.006 ) consisted of a straight channel containing one major pool-riffle structure and with bed material of medium cobbles (Wallis et al. 1989). River flow rates, which were in the range of 300-2200 L/s, were evaluated from the tracer data using dilution gauging. They agreed closely with observations from a nearby water authority operated flow gauging weir (Wallis et al. 1987). Data were recorded at a fixed sampling interval of $15 \mathrm{~s}$. Consequently, the tracer profiles were described by between 50 and 150 data points with the lowest resolution occurring at the upstream site at the highest flow rate and the highest resolution occurring at the downstream site at the lowest flow rate.

Prior to use the upstream data of each experiment was scaled (by the ratio of upstream to downstream concentration profile areas) to remove any effect from lateral inflow, non-conservative behaviour of tracer or calibration errors. Generally, this was not a major issue with the mean downstream to upstream concentration profile area ratio being $0.985( \pm 0.052)$. This also suggests that, in general, the tracer was well mixed in all the experiments.

\section{Optimization}

For each experiment, the four model parameters $\left(U_{\mathrm{TS}}, D_{\mathrm{TS}}\right.$, $k_{1}$ and $k_{2}$ ) were estimated by optimizing the fit of the temporal solute concentration profile simulated by the TSM to that observed at the downstream end of the reach. The observed upstream temporal solute concentration from the same experiment provided the upstream boundary condition. Optimization was achieved by minimizing the sum of squared residuals using a modified Levenberg-Marquardt algorithm (Press et al. 1992) as summarized in Manson et al. (2016). This follows common practice, but the possibility that other objective function formulations may have an impact on optimized parameter values is worthy of consideration.

The influence of model resolution was investigated by undertaking the optimization for the following cases: space steps of $0.64,1.28,2.56$ and $5.12 \mathrm{~m}$ all with a time step of
$15 \mathrm{~s}$; time steps of 7.5, 15 and $30 \mathrm{~s}$ all with a space step of $1.28 \mathrm{~m}$. The choice of space steps was based on an arbitrary decision to initially divide the reach into 100 space steps, followed by obvious lower and higher resolutions. As noted below, the spatial resolution of the reach is rather less important than the spatial resolution of the solute cloud being modelled. Fewer time step cases then space step cases were considered because whilst it is easy to change the space step, changes to the time step require changes to the upstream boundary condition. An increase in time step is relatively easy to accommodate because data can be omitted from the observed solute concentration profile (assuming this leaves sufficient data to adequately represent the shape of the original profile), but a reduction in time step requires data to be interpolated between observed values. This is difficult to do reliably, particularly in regions of high curvature such as around the peak and around the initial rise of the profile above the background signal. Hence, only two cases, one either side of the original time step of $15 \mathrm{~s}$, were used: every other data point was removed to achieve a time step of $30 \mathrm{~s}$; linear interpolation was employed to generate the data at a time step of $7.5 \mathrm{~s}$.

It is important to emphasize that the magnitudes of the space and time steps control the magnitude of the numerical errors introduced into the solution of the model equations. Also, they control the resolution at which the event is modelled, but not in terms of the physical size of the river or the period of time over which solute concentrations are observed. Instead, the extent and duration of the solute cloud being modelled are the key scales against which the space and time steps need to be compared in order to quantify the spatial and temporal resolutions at which the event is modelled. Hence, as described in Wallis and Manson (2018), the spatial and temporal resolutions of a solute cloud, respectively, were evaluated by dividing its spatial extent by the space step, and by dividing its temporal duration at the upstream end of the reach by the time step. The spatial extent of a solute cloud was evaluated as the product of its temporal duration and its centroid velocity, with the former being evaluated as the time difference between the start and end of the cloud's upstream temporal concentration profile. The start and end of a profile were defined as the times at which the concentration was $10 \%$ of the peak concentration. The centroid velocity was evaluated from the first and zeroth temporal moments of the profiles.

\section{Results and discussion}

A total of 150 optimizations were undertaken of which only about 10 failed to produce physically realistic parameter values. There was no obvious cause of, or pattern to the distribution of, the failures. It is, however, possible that in these 
cases the initial values used in the optimization were not compatible with the search for the global minimum. They were treated as outliers and were not included in the analysis of the results. Optimized values of all four model parameters were found to be sensitive to the space step and time step used. Importantly, for each tracer experiment they converged towards what might be termed their "true" values as the spatial and temporal discretization became more refined. The convergence was smooth and showed no evidence of interaction between the parameters. The effect of increasing the spatial resolution is illustrated in Fig. 1 which shows the percentage absolute differences in $U_{\mathrm{TS}}, D_{\mathrm{TS}}, k_{1}, k_{2}$ and $A_{\mathrm{s}} / A$ between successive pairs of space steps for all experiments. $A_{\mathrm{s}} / A$, evaluated as the ratio of $k_{1}$ to $k_{2}$, is an important

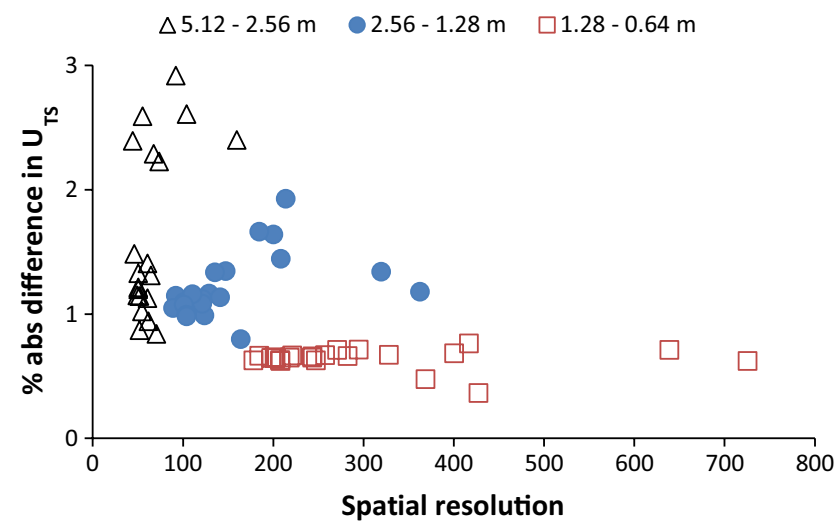

(a) Effect of space step on $U_{T S}$

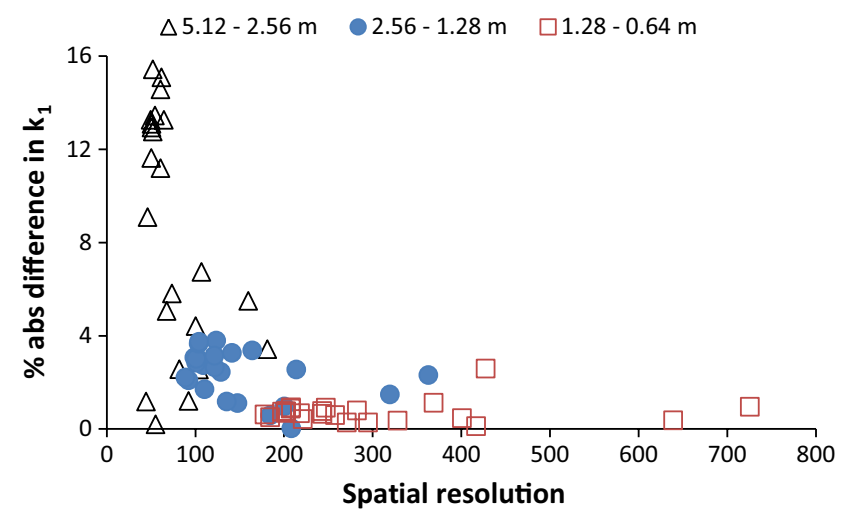

(c) Effect of space step on $k_{1}$

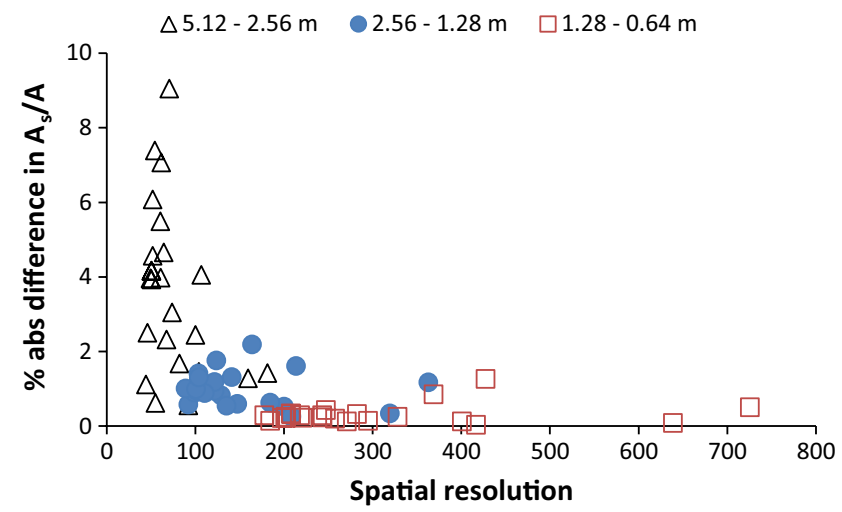

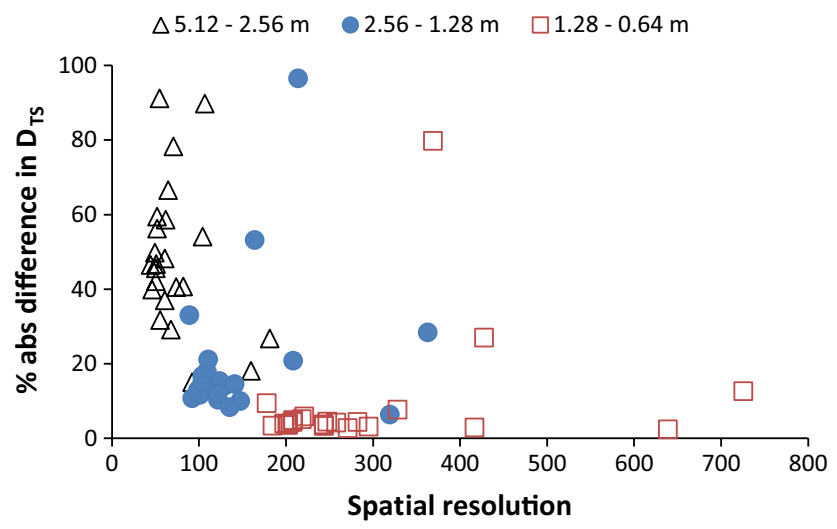

(b) Effect of space step on $D_{T S}$

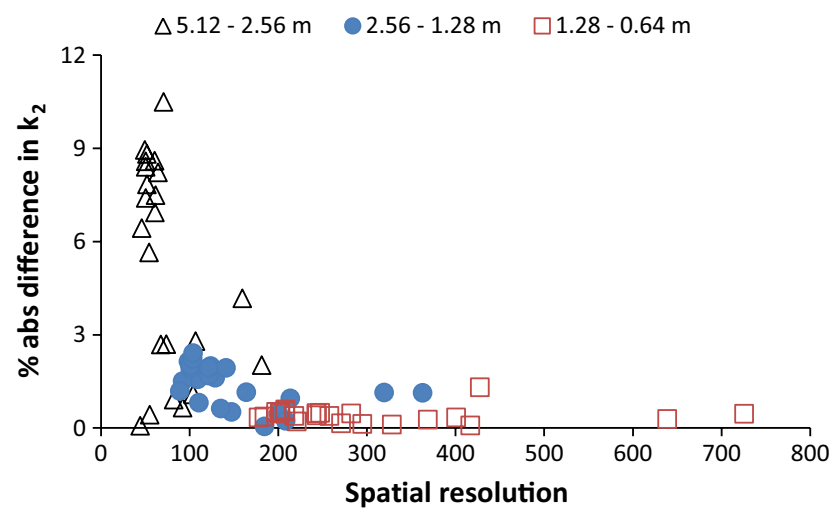

(d) Effect of space step on $k_{2}$

(e) Effect of space step on $A_{s} / A$

Fig. 1 Variation of change in optimized parameter values, caused by halving the space step, with spatial resolution: time step $15 \mathrm{~s}$ (each symbol represents one tracer experiment; spatial resolution is the ratio of tracer cloud length to space step) 
parameter in transient storage studies because it quantifies the physical size of the transient storage zones in relation to the physical size of the main channel.

In each panel, the triangles show the percentage absolute difference between the parameter values obtained using space steps of 5.12 and $2.56 \mathrm{~m}$, and these are plotted against the spatial resolutions corresponding to the $2.56 \mathrm{~m}$ space step. The circles and open squares show the results presented in the same way for successive pairs of reducing space step. All these results were generated from optimizations that used a time step of $15 \mathrm{~s}$.

It is evident that not only is there a reduction in the percentage difference for all the parameters with successive pairs of reducing space steps but also there is considerable variation in spatial resolution between all the experiments even when the space step is fixed. This occurs for several reasons. Most importantly, the fact that the tracer was pumped into the river over a period of about a minute meant that the tracer cloud was initially (i.e. before it reached the upstream observation location) longer in experiments undertaken at high river flow rates than in experiments undertaken at lower river flow rates. This occurred because of the higher velocity of the water in the former cases compared to the latter cases. In addition, reach travel time and overall longitudinal dispersion (main channel shear flow plus transient storage) rates varied with river flow rate, the former decreased, whilst the latter increased. In general, however, the spatial resolution increased approximately linearly with river flow rate (from about 100 to about 200 for the $1.28 \mathrm{~m}$ space step case), suggesting that the pumped tracer release system was the dominant issue. Results for all five parameters are summarized in Table 1 which shows percentage differences averaged over all experiments. Clearly, all five parameters converge with reducing space step. $D_{\mathrm{TS}}$ and $U_{\mathrm{TS}}$ are the most and the least sensitive parameters, respectively: $k_{2}$ is less sensitive than $k_{1}$.

The effect of increasing the temporal resolution is shown in Fig. 2, which is presented in the same way as Fig. 1. The space step was $1.28 \mathrm{~m}$ in all these cases. Clearly, the trends are similar to before: there is a reduction in the percentage difference in all parameter values with successive pairs of reducing time step. Table 2 shows percentage differences averaged over all experiments. Clearly, all five parameters converge with reducing time step. As was found with the space step, $D_{\mathrm{TS}}$ and $U_{\mathrm{TS}}$ are the most and the least sensitive parameters to the time step, respectively: $k_{2}$ is less sensitive than $k_{1}$. Again, as before, there were variations in temporal resolution between experiments, this time with a reduction from about 40 to about 20 for the 15 s time step case. The reduction reflects the fact that a solute cloud passes a fixed observation location more quickly at higher river flow rates than at lower river flow rates. Thus, when using a fixed sampling interval, higher river flow rate events will be observed at a poorer temporal resolution than lower river flow rate events.

It is noticeable in the figures that the temporal resolutions covered by the results are lower than the spatial resolutions covered. This is quantified in the last column of Tables 1 and 2 which show the average resolution for each case. The only approximately comparable spatial and temporal resolutions are the first row in Table 1 and the second row in Table 2.

Interestingly, the mean percentage differences in four of the parameters are also similar, but $D_{\mathrm{TS}}$ appears to be more sensitive to the space step than to the time step.

The optimized TSM fitted all the observed downstream concentration profiles well, with fits improving as model resolution increased. For example using a time step of $15 \mathrm{~s}$, root mean square errors between observed and modelled concentrations were as follows for space steps of 5.12, 2.56, 1.28 and $0.64 \mathrm{~m}$, respectively: $0.0173,0.0129,0.0120$ and $0.0118 \mu \mathrm{g} / \mathrm{L}$ for an experiment with a river flow rate of 469 $\mathrm{L} / \mathrm{s} ; 0.0061,0.0057,0.0057$ and $0.0057 \mu \mathrm{g} / \mathrm{L}$ for an experiment with a river flow rate of $1460 \mathrm{~L} / \mathrm{s}$. Similarly, using a space step of $1.28 \mathrm{~m}$, root mean square errors between observed and modelled concentrations were as follows for time steps of 30,15 and $7.5 \mathrm{~s}$, respectively: $0.0248,0.0120$ and $0.0086 \mu \mathrm{g} / \mathrm{L}$ for an experiment with a river flow rate of $469 \mathrm{~L} / \mathrm{s} ; 0.0086,0.0057$ and $0.0044 \mu \mathrm{g} / \mathrm{L}$ for an experiment with a river flow rate of $1460 \mathrm{~L} / \mathrm{s}$.

A more meaningful assessment of model fit across all the experiments was achieved by calculating the normalized root mean square errors between observed and modelled concentrations. The normalized root mean square error for any particular case was evaluated by dividing the root mean square error between observed and modelled concentrations by the maximum observed solute concentration. Averaged over all experiments (all for a time step of $15 \mathrm{~s}$, as earlier) normalized root mean square errors were $0.0113,0.0095$, 0.0092 and 0.0091 for space steps of $5.12,2.56,1.28$ and
Table 1 Mean percentage differences in optimized parameters between pairs of space steps

\begin{tabular}{llrlllc}
\hline $\begin{array}{l}\text { Space step change } \\
(\mathrm{m})\end{array}$ & $U_{\mathrm{TS}}$ & $D_{\mathrm{TS}}$ & $k_{1}$ & $k_{2}$ & $A_{\mathrm{s}} / A$ & $\begin{array}{c}\text { Average } \\
\text { spatial reso- } \\
\text { lution }\end{array}$ \\
\hline $5.12-2.56$ & 1.96 & 48.33 & 8.95 & 5.14 & 3.62 & 75 \\
$2.56-1.28$ & 1.20 & 15.17 & 2.37 & 1.38 & 1.00 & 150 \\
$1.28-0.64$ & 0.64 & 5.74 & 0.71 & 0.40 & 0.30 & 300 \\
\hline
\end{tabular}




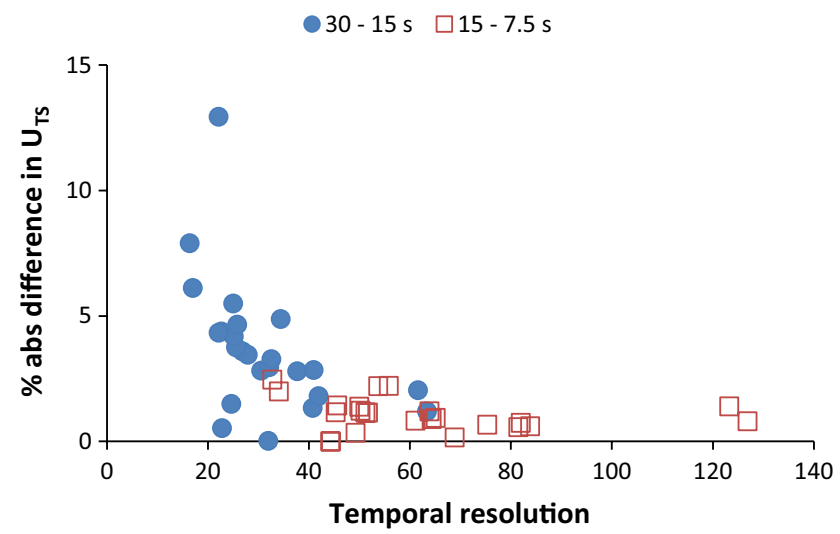

(a) Effect of time step on $U_{T S}$

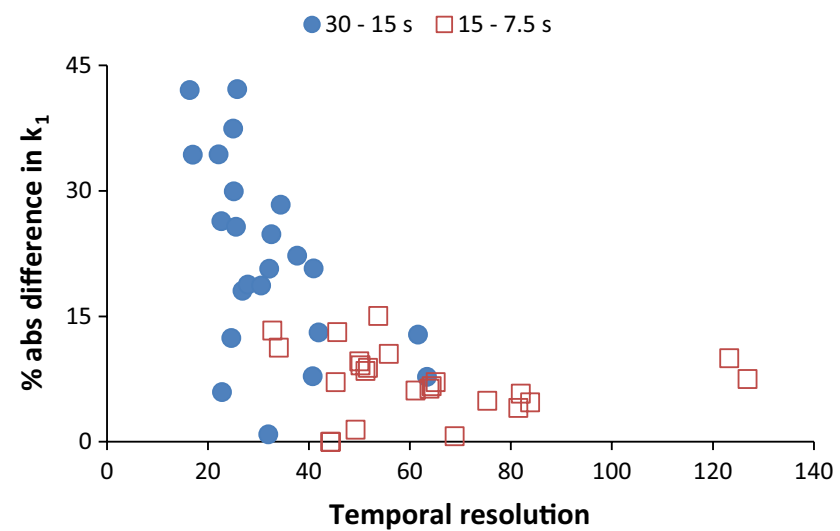

(c) Effect of time step on $k_{1}$

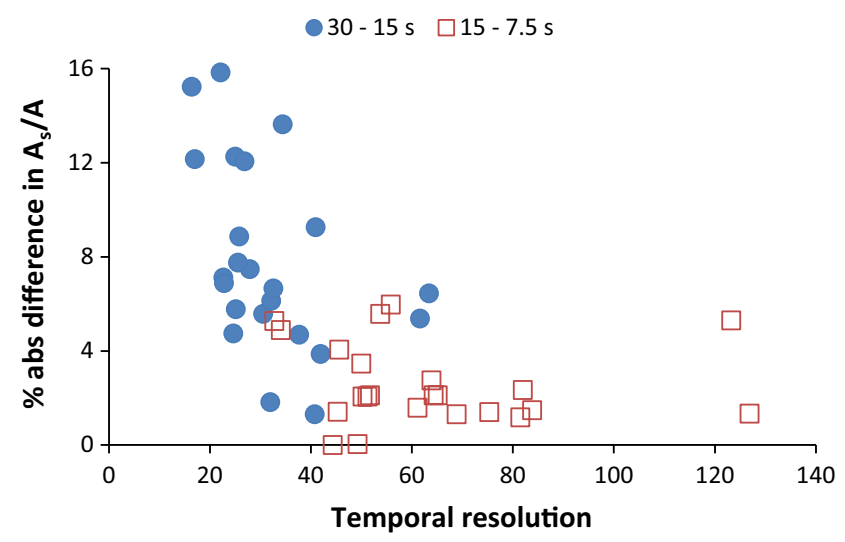

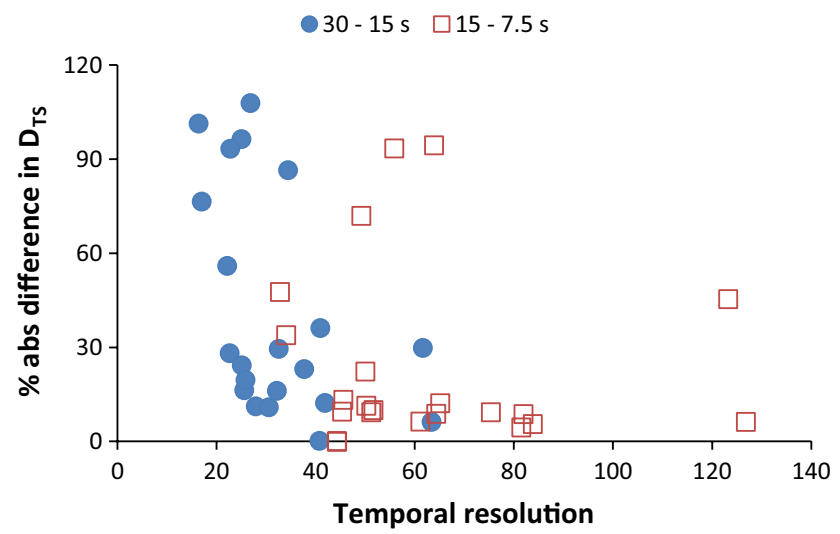

(b) Effect of time step on $D_{T S}$

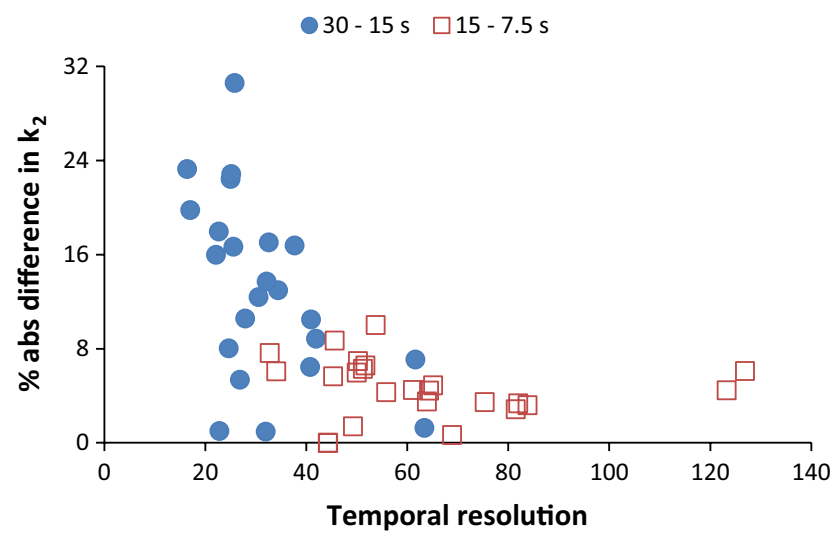

(d) Effect of time step on $k_{2}$

(e) Effect of time step on $A_{S} / A$

Fig. 2 Variation of change in optimized parameter values, caused by halving the time step, with temporal resolution: space step $1.28 \mathrm{~m}$ (each symbol represents one tracer experiment; temporal resolution is the ratio of tracer cloud length to time step)

Table 2 Mean percentage differences in optimized parameters between pairs of time steps

\begin{tabular}{lllrrrr}
\hline $\begin{array}{l}\text { Time step change } \\
(\mathrm{s})\end{array}$ & $U_{\mathrm{TS}}$ & $D_{\mathrm{TS}}$ & $k_{1}$ & $k_{2}$ & $A_{\mathrm{s}} / A$ & $\begin{array}{l}\text { Average } \\
\text { temporal } \\
\text { resolution }\end{array}$ \\
\hline $30-15$ & 3.52 & 27.90 & 23.05 & 14.59 & 7.26 & 31 \\
$15-7.5$ & 1.21 & 20.84 & 8.04 & 5.15 & 2.74 & 62 \\
\hline
\end{tabular}


$0.64 \mathrm{~m}$, respectively. Similarly, normalized root mean square errors between observed and modelled concentrations averaged over all experiments (all for a space step of $1.28 \mathrm{~m}$, as earlier) were $0.0150,0.0092$ and 0.0074 for time steps of 30 , 15 and $7.5 \mathrm{~s}$, respectively.

An indication of the significance of the dependence of optimized parameter values on model resolution was gained by evaluating the percentage difference between results obtained using a space step of $5.12 \mathrm{~m}$ with a time step of $30 \mathrm{~s}$ (coarse resolution) and those obtained using a space step of $1.28 \mathrm{~m}$ with a time step of $7.5 \mathrm{~s}$ (fine resolution). Means and standard deviations of these differences evaluated over all experiments are shown in Table 3.

Although differences in $U_{\mathrm{TS}}$ are very small, differences in $D_{\mathrm{TS}}, k_{1}$ and $k_{2}$ are substantial. Figure 3 shows how these differences vary between tracer experiments, where they are plotted against river flow rate (determined from the tracer data using dilution gauging). It appears that differences in $U_{\mathrm{TS}}$ increase with increasing river flow rate whilst differences in $k_{1}$ and $k_{2}$ decrease with increasing river flow rate. There is no clear pattern for $D_{\mathrm{TS}}$ and $A_{\mathrm{s}} / A$.

Further detail is shown in Fig. 4 where the individual optimized parameter values from the coarse and fine optimizations are plotted together, again against river flow rate. The two sets of velocities are very close to each other and, in comparison to the fine resolution values, there are about the same number of overestimates as there are underestimates in the coarse resolution values. About $75 \%$ of the dispersion coefficients are underestimated in the coarse resolution case. In contrast about $85 \%$ of both exchange rates and the area ratio are overestimated in the coarse resolution case. Other features of the dispersion coefficient results, in particular, worth highlighting are the scatter and the very small values. These may reflect that the optimum model fit to the data is insensitive to this parameter, however, we have not investigated this.

The real significance of such potential errors lies in the use of the parameter values when formulating predictive equations for the model parameters for use in river reaches where no tracer experiments have been undertaken (e.g. Cheong et al. 2007; O'Connor et al. 2010). Clearly, parameter values obtained using numerical solutions of the TSM which employ poor spatial and temporal resolutions should not be used in such exercises. Unfortunately there is little or

Table 3 Percentage differences in optimized parameters between coarse and fine resolutions

\begin{tabular}{lllllr}
\hline & $U_{\mathrm{TS}}$ & $D_{\mathrm{TS}}$ & $k_{1}$ & $k_{2}$ & $A_{\mathrm{s}} / A$ \\
\hline Mean & 2.19 & 68.75 & 33.69 & 20.28 & 10.87 \\
Standard & 1.50 & 20.06 & 16.88 & 11.06 & 5.24 \\
\begin{tabular}{l} 
deviation \\
\hline
\end{tabular} & & & & & \\
\hline
\end{tabular}

no evidence that such matters have been considered in previous work because the model resolutions at which parameter estimates have been obtained by optimizing the TSM to observed temporal concentration profiles are rarely, if at all, quoted alongside the published parameter values. For example, in a sample of seven published articles concerning the application of the TSM to tracer data (Hart et al. 1999; Gooseff et al. 2003a; Jin and Ward 2005; Cheong et al. 2007; Camacho and Gonzalez 2008; O'Connor et al. 2010; Kelleher et al. 2013) only one of them clearly stated what space step or time step had been used in the modelling, and there was no mention of spatial or temporal resolution in any of them. Only in 4 of them was the experimental sampling interval in the concentration profiles stated. These ranged from 10-300 s, with the majority being greater than the $15 \mathrm{~s}$ in the river Brock data. Hence, in view of the results presented above, it is likely that some unreliable parameter values have been reported in the literature, and therefore it is possible that some unreliable values have been used in the development of predictive equations for the TSM parameters.

The findings described above should provide food for thought for workers designing tracer experiments for use with parameter optimization of the TSM. In particular, we would emphasize the merits of collecting observed solute concentrations at the smallest time step possible and recognizing that high river flow rate events are particularly vulnerable to being observed too coarsely.

Finally, Fig. 4 provides evidence for how the TSM parameters vary with river flow rate, which is an issue that has not been addressed by other workers except in a very few studies (Hart et al. 1999; Gooseff et al. 2003a; Jin and Ward 2005; Camacho and Gonzalez 2008). Clearly, $U_{\text {TS }}$ and $k_{1}$ and $k_{2}$ increase with river flow rate, as previously discussed in Wallis and Manson (2018), yet $A_{\mathrm{s}} / A$ is approximately constant at a value of about $0.3 . D_{\mathrm{TS}}$ shows no particular pattern although the fine resolution results are more closely grouped, and in this case, it could be argued that a constant value of about $0.25 \mathrm{~m}^{2} / \mathrm{s}$ adequately describes the data. Similar values of $D_{\mathrm{TS}}$ were reported in the four studies referred to above, which were single reach studies undertaken on similar sized or smaller rivers and at similar river flow rates to the river Brock tracer experiments. Interestingly, 50 of the $51 D_{\mathrm{TS}}$ values provided in those sources are $<0.6 \mathrm{~m}^{2} / \mathrm{s}$. Similarly, in about 60 optimizations of the TSM to mountain stream data reported in Manson et al. (2016), all the $D_{\text {TS }}$ values were $<0.4 \mathrm{~m}^{2} / \mathrm{s}$. Furthermore, optimization of the advection-dispersion model (ADM) to the river Brock data yielded dispersion coefficients that increased from about $1-5 \mathrm{~m}^{2} / \mathrm{s}$ over the river flow rate range of $300-2200 \mathrm{~L} / \mathrm{s}$. The ADM is a simplified version of the TSM in which the transient storage terms are ignored, i.e. it is simply Eq. (1) with the final 


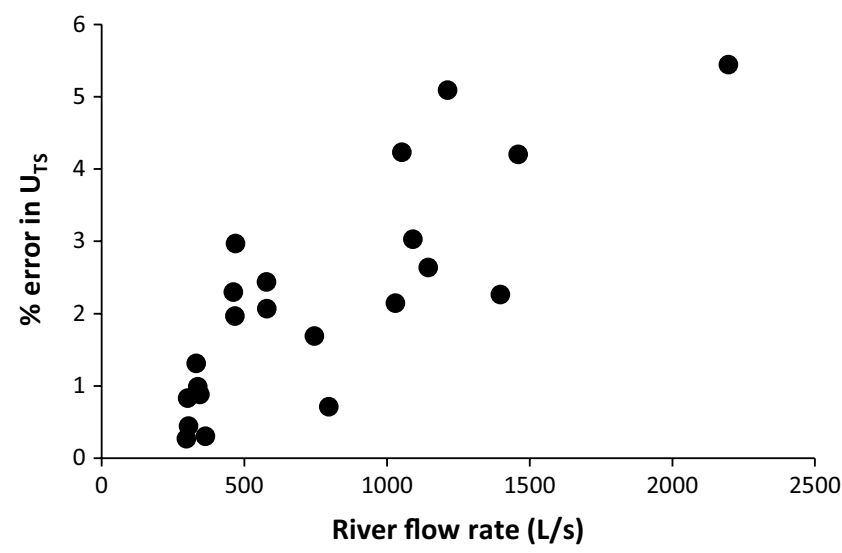

(a) $\%$ difference in $U_{T S}$

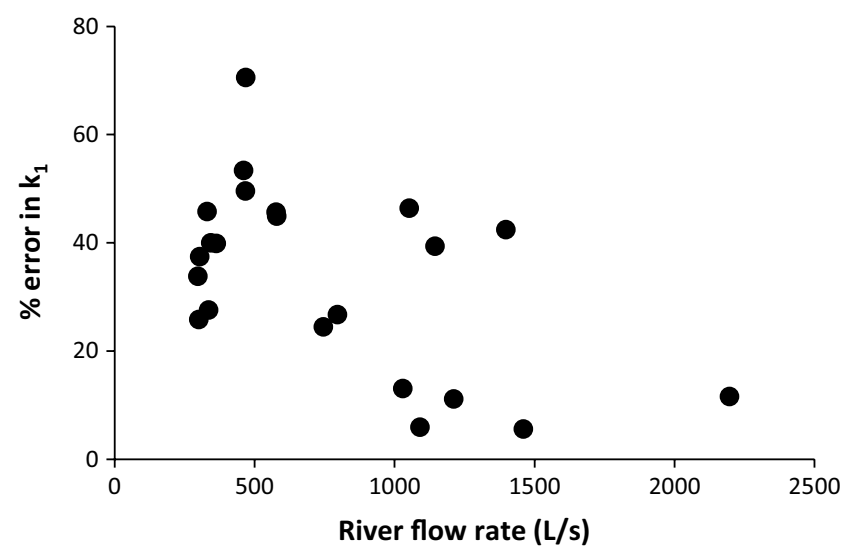

(c) $\%$ difference in $k_{l}$

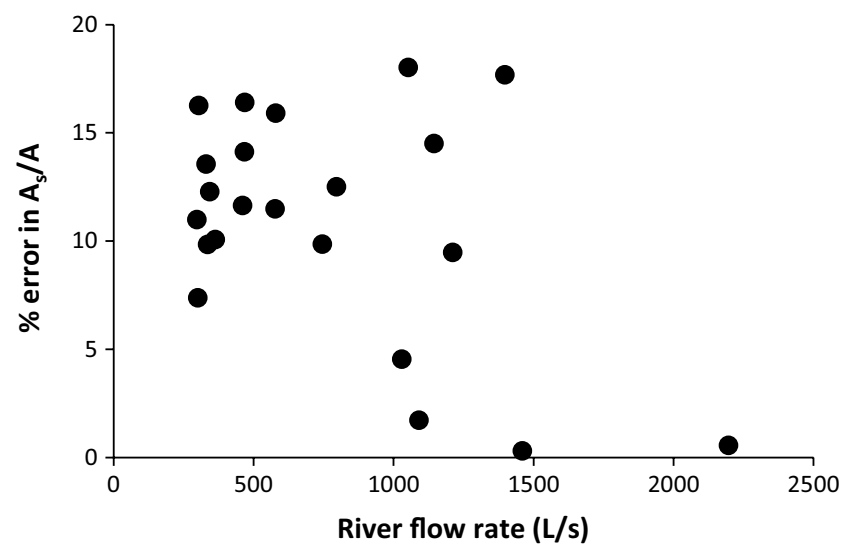

(e) $\%$ difference in $A_{S} / A$

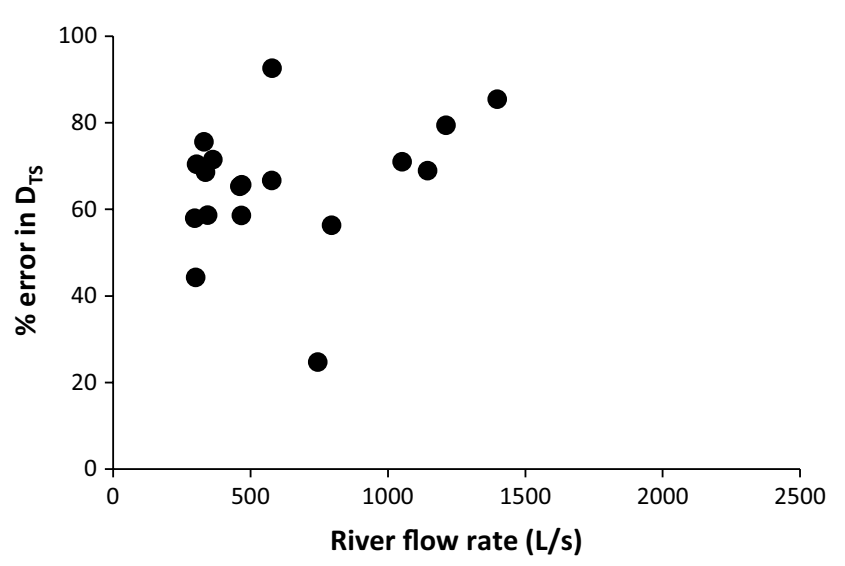

(b) $\%$ difference in $D_{T S}$

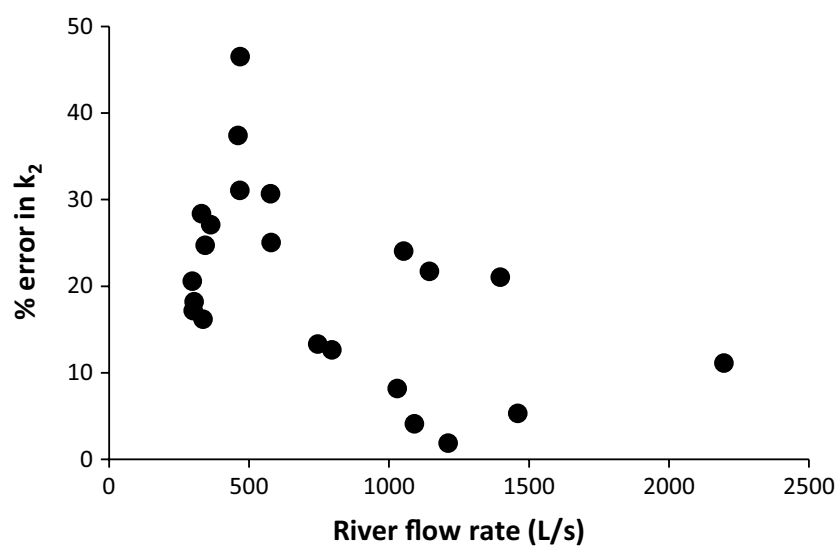

(d) $\%$ difference in $k_{2}$

Fig. 3 Variation of $\%$ difference in optimized parameters between coarse and fine resolutions with river flow rate

term on the right-hand side omitted. Optimizations were obtained in the same way as for the TSM model and used a space step of $1.28 \mathrm{~m}$ and a time step of $15 \mathrm{~s}$. These dispersion coefficients are estimates of the overall longitudinal dispersion taking place in the reach, caused by shear flow in the main channel and transient storage, as measured by the increase in variance of the temporal concentration profile between upstream and downstream observation locations. Clearly, these results imply that not only are the estimates of $D_{\mathrm{TS}}$ in the river Brock small in numerical terms, 


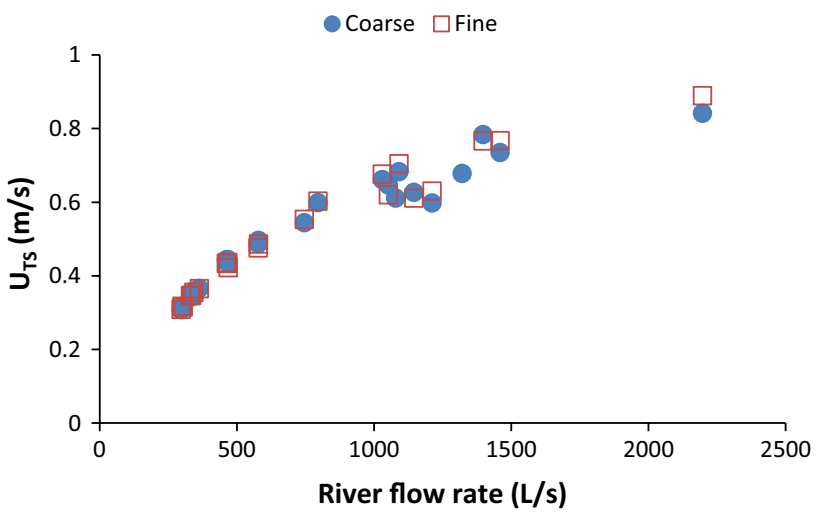

(a) Optimized $U_{T S}$

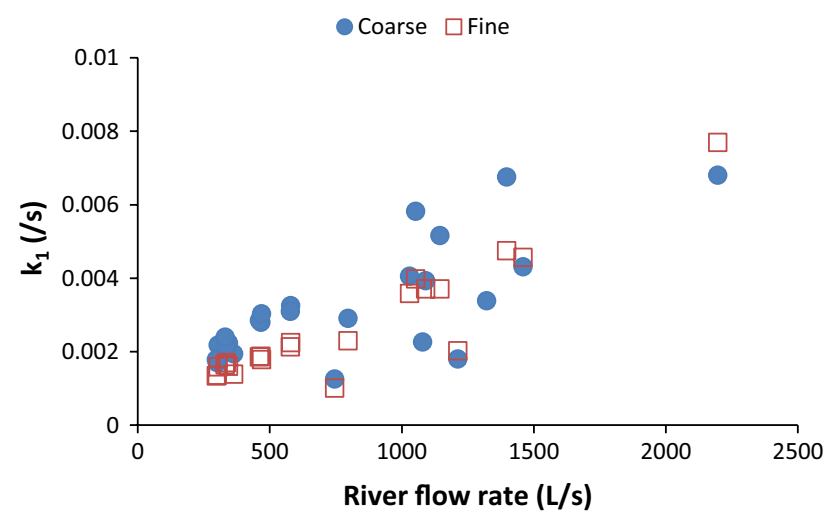

(c) Optimized $k_{1}$

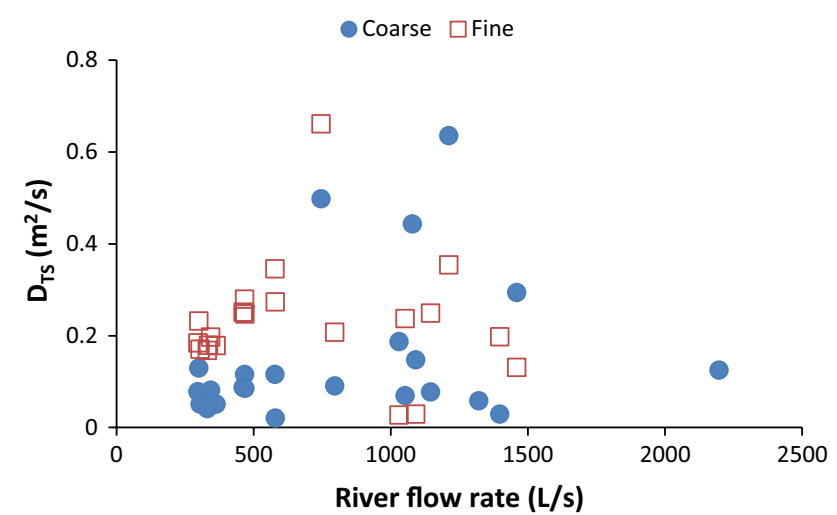

(b) Optimized $D_{T S}$

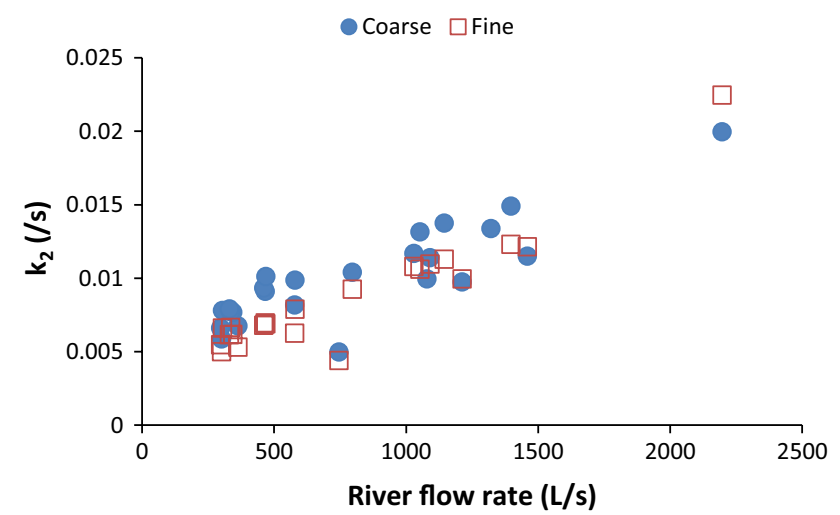

(d) Optimized $k_{2}$

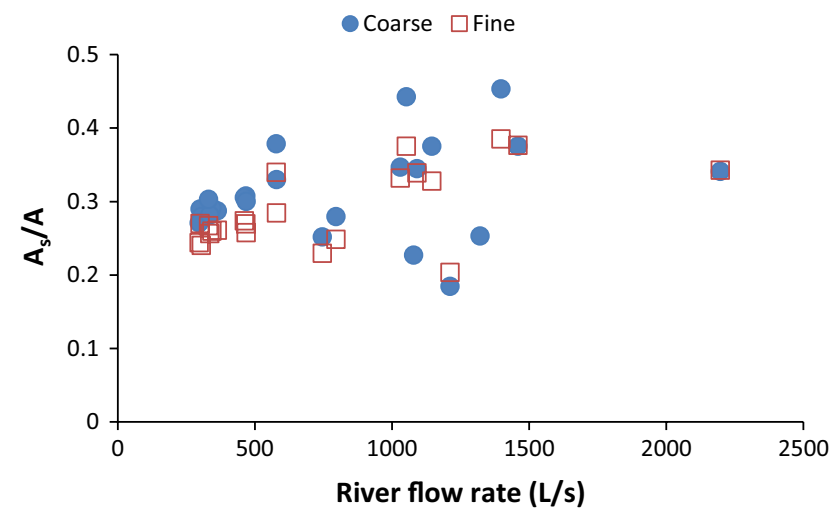

(e) Optimized $A_{s} / A$

Fig. 4 Variation of optimized parameters with river flow rate for coarse and fine resolutions

but also that transient storage is the dominant dispersive process in the reach. In view of this, and the similarly small $D_{\mathrm{TS}}$ values in the other sources referred to above, we postulate that omitting the dispersion term from the TSM, thus creating a three-parameter model, whose parameters might be more robustly identified than those of the fourparameter model, is worthy of examination.

\section{Conclusions}

By optimizing the TSM to observed temporal solute concentration profiles using different numerical resolutions in space and time, it has been demonstrated that the resultant estimates of the model parameters are dependent on the resolutions used. Although this will not be a surprise to 
numerical modellers who are well aware of the concept of grid-independent solutions, there is little evidence that the significance of numerical resolution has been recognized by workers using the TSM. In tests using 25 observed solute transport events from the river Brock in the north-west of England, mean percentage differences in parameter values between a coarse resolution model and a fine resolution model were of the order of $2 \%$ for the velocity, $70 \%$ for the shear flow dispersion coefficient and 30\% and 20\% for the two exchange rates. It would seem prudent that in applications of the TSM, minimum spatial and temporal resolutions of the order of 100 are used, followed by a repeat optimization at a finer resolution(s), to ensure that estimates of transport and mixing parameters are not significantly contaminated by model discretization errors. Also, we recommend that model resolutions should be published alongside the optimized parameter values. Evidence of small shear flow dispersion coefficients in the river Brock and a few other rivers of similar size suggests that a three-parameter version of the TSM is worthy of examination.

\section{Compliance with ethical standards}

Conflict of interest The authors declare that they have no conflict of interest.

Open Access This article is distributed under the terms of the Creative Commons Attribution 4.0 International License (http://creativeco mmons.org/licenses/by/4.0/), which permits unrestricted use, distribution, and reproduction in any medium, provided you give appropriate credit to the original author(s) and the source, provide a link to the Creative Commons license, and indicate if changes were made.

\section{References}

Bencala KE, Walters RA (1983) Simulation of solute transport in a mountain pool-and-riffle stream: a transient storage model. Water Resour Res 19:718-724

Briggs MA, Gooseff MA, Arp CD, Baker MA (2009) A method for estimating surface transient storage for streams with concurrent hyporheic storage. Water Resour Res 45:W00D27

Camacho LA, Gonzalez RA (2008) Calibration and predictive ability of longitudinal solute transport models in mountain streams. Environ Fluid Mech 8:597-604

Cheong TS, Younis BA, Seo IW (2007) Estimation of key parameters in model for solute transport in rivers and streams. Water Resour Manag 21:1165-1186

Gooseff MN, McGlynn BL, McGlynn RS (2003a) Transient storage processes and stream discharge recession in a headwater stream, Maimai, New Zealand. Proc N Am Benthol Soc Annu Meet

Gooseff MN, Wondzell SM, Haggerty R, Anderson J (2003b) Comparing transient storage modeling and residence time distribution (RTD) analysis in geomorphically varied reaches in the Lookout Creek basin, Oregon, USA. Adv Water Resour 26:925-937

Hart DR, Mulholland PJ, Marzolf ER, DeAngelis DL, Hendricks SP (1999) Relationships between hydraulic parameters in a small stream under varying flow and seasonal conditions. Hydrol Process 13:1497-1510
Jin H-S, Ward GM (2005) Hydraulic characteristics of a small coastal plain stream of the southeastern United States: effects of hydrology and season. Hydrol Process 19:4147-4160

Kelleher C, Wagener T, McGlynn B, Ward AS, Gooseff MN, Payn RA (2013) Identifiability of transient storage model parameters along a mountain stream. Water Resour Res 49:5290-5306

Liao Z, Cirpka OA (2011) Shape-free inference of hyporheic traveltime distributions from synthetic conservative and "smart" tracer tests in streams. Water Resour Res 47:W07510

Manson JR, Wallis SG, Hope D (2001) A conservative semi-Lagrangian transport model for rivers with transient storage zones. Water Resour Res 37:3321-3329

Manson JR, Wallis SG, Demars BOL, Mick JD, Gislason GM, Olafsson JS, Friberg N (2016) A comparison of three solute transport models using mountain stream tracer experiments. In: Rowinski PM, Marion A (eds) Hydrodynamic and mass transport at freshwater aquatic interfaces. Springer, Switzerland, pp 77-90

Marion A, Zaramella M, Bottacin-Busolin A (2008) Solute transport in rivers with multiple storage zones: the STIR model. Water Resour Res 44:W10406

O'Connor BL, Miki H, Harvey JW (2010) Predictive modelling of transient storage and nutrient uptake: implications for stream restoration. J Hyd Eng Am Soc Civ Eng 136:1018-1032

Press WH, Teukolsky SA, Vetterling WT, Flannery BP (1992) Numerical recipes in C: the art of scientific computing, 2nd edn. Cambridge University Press, Cambridge

Runkel RL (1998) One-dimensional transport with inflow and storage (OTIS): a solute transport model for streams and rivers. Water Resour Invest Rep 98-4018 (U S Geol Surv, Denver, Co)

Runkel RL, Chapra SC (1993) An efficient numerical solution of the transient storage equations for solute transport in small streams. Water Resour Res 29:211-215

Rutherford JC (1994) River Mixing. Wiley, Chichester

Thackston EL, Krenkel PA (1967) Longitudinal mixing in natural streams. J Sanit Eng Div Proc Am Civ Soc Eng 93:67-90

Wagener T, Camacho LA, Wheater HS (2002) Dynamic identifiability analysis of the transient storage model for solute transport in rivers. J Hydroinformatics 94:199-211

Wagner BJ, Harvey JW (1997) Experimental design for estimating parameters of rate-limited mass transfer: analysis of stream tracer studies. Water Resour Res 33:1731-1741

Wallis SG, Manson JR (2018) Flow dependence of the parameters of the transient storage model. In: Kalinowska MB, Mrokowska MM, Rowinski PM (eds) Free surface flows and transport processes. Springer, Cham, pp 477-488

Wallis SG, Blakeley C, Young PC (1987) A microcomputer based fluorometric data logging and analysis system. J Inst Water Eng Sci 41:122-134

Wallis SG, Young PC, Beven KJ (1989) Experimental investigation of the aggregated dead zone model for longitudinal solute transport in stream channels. Proc Inst Civ Eng Part 2(87):1-22

Wallis SG, Osuch M, Manson JR, Romanowicz R, Demars BOL (2013) On the estimation of solute transport parameters for rivers. In: Rowinski P (ed) Experimental and computational solutions of hydraulic problems. Springer, Berlin, pp 415-425

Worman A, Wachniew P (2007) Reach scale and evaluation methods as limitations for transient storage properties in streams and rivers. Water Resour Res 43:W10405

Zaramella M, Marion A, Lewandowski J, Nutzman G (2016) Assessment of transient storage exchange and advection-dispersion mechanisms from concentration signatures along breakthrough curves. J Hydrol 538:795-801 